\title{
Potential of Oxytocin in the Treatment of Schizophrenia
}

\author{
Paul D. Shilling and David Feifel \\ Department of Psychiatry, University of California, San Diego, La Jolla, CA 92093
}

\begin{abstract}
Schizophrenia is a heterogeneous, debilitating disorder characterized by three distinct sets of clinical features: positive symptoms, negative symptoms and cognitive deficits. Extant antipsychotic drugs have been most successful at treating the positive symptoms of patients that suffer from schizophrenia but have minimal therapeutic effects on negative symptoms and cognitive deficits, which are the symptoms that best predict the poor prognosis of these patients. Therefore, there has been a major effort towards identifying compounds that alleviate these symptoms.

Oxytocin (OT) is a nonapeptide that regulates peripheral reproductive-relevant functions, and also acts as a neurotransmitter in the brain. Converging evidence from both preclinical and clinical research suggests that OT may have therapeutic efficacy for the positive symptoms, negative symptoms and cognitive deficits of schizophrenia. In the majority of the small-randomized placebo controlled clinical trials conducted to date, OT has shown particular promise in its potential to treat the intractable negative symptoms and social cognitive deficits exhibited by most of the patients with this debilitating disorder.

In this leading article, we summarize the clinical evidence relevant to 1) endogenous OT and schizophrenia, and 2) the putative therapeutic effects of OT on each of the three clinical domains.
\end{abstract}

\section{Keywords}

oxytocin; schizophrenia; positive symptoms; negative symptoms; cognitive deficits; antipsychotic

\section{Introduction}

Schizophrenia (SCZ) is a heterogeneous, debilitating disorder characterized by positive symptoms, negative symptoms and cognitive deficits. Positive symptoms comprise perceptual aberrations such as auditory and visual hallucinations, delusions such as fixed or false beliefs, and disorganized behavior or speech. Negative symptoms include deficits in motivation (avolition), anticipation of pleasure (anhedonia), social interaction (asociality), verbal communication (alogia), and affect. In addition, most people with SCZ also exhibit

Correspondence to: David Feifel, MD, PhD, Department of Psychiatry, University of California, San Diego Medical Center, 200 West Arbor Drive, San Diego, CA 92103-8218, (619) 543-2485 [Telephone], (619) 543-3738 [FAX], dfeifel@ucsd.edu.

Disclosures

DF is named inventor of a patent filing by UCSD involving the use of oxytocin. PDS reports no biomedical financial interests or potential conflicts of interest. 
deficient cognitive processing further impairing their ability to function. Seven specific domains of cognitive impairment were identified by NIMH-MATRICS initiative in patients with SCZ including working memory, attention/vigilance, visual and verbal learning and memory, information processing speed, reasoning and problem solving, and social cognition [1]. Although positive symptoms are required for a diagnosis of schizophrenia, a subset of patients do not exhibit negative symptoms and/or cognitive deficits consistent with substantial clinical heterogeneity among patients meeting the diagnostic criteria for SCZ [2].

When taken consistently by patients with SCZ, current antipsychotic drugs (APDs) provide substantial relief from the positive symptoms. The mechanism of this effect is the ability of these drugs to bind and reduce neural transmission through D2 receptors in the mesolimbic pathway. Whereas this is considered the sole mechanism of action for first generation or 'typical' APDs (e.g., haloperidol), second generation atypical APDs (e.g., clozapine) have an additional mechanism of binding serotonin-2A (5HT2A) receptors and these newer APDs are associated with reduced extrapyramidal side effects and possibly modest increased efficacy against negative symptoms and cognitive deficits [3-8]. Unfortunately, current APDs have, at best, have produced minimal therapeutic effects on the negative symptoms and cognitive deficits associated with poor functioning and prognosis $[9,10]$. Therefore, the development of medications aimed at alleviating the negative symptoms and cognitive deficits of SCZ, highly chronic disabling symptoms of this disorder, are of highest priority.

Recently, converging results from preclinical and clinical studies suggest that activation of the oxytocin (OT) system may produce therapeutic effects on all three of symptom domains of SCZ. OT is a nonapeptide released from the hypothalamus that is best known for its action on uterine contractions and lactation. Of relevance to its potential therapeutic effects in SCZ, OT exhibits neurotransmitter activity in the brain and recently has become strongly associated with positive regulation of affiliation and social cognition, in addition to its role in learning and memory, and stress [11].

In this article, we summarize clinical studies aimed at investigating 1) endogenous OT and SCZ, and 2) the potential for OT or OT-mimetics to provide relief from the positive symptoms, negative symptoms and the cognitive deficits that torment patients with this devastating disorder.

\section{The role of OT in the CNS}

Oxytocin a nine-amino acid peptide that is highly conserved across a wide variety of species $[12,13]$ and is best known for its role in regulating peripheral reproductive-relevant functions such as uterine contractions in parturition and lactation [14, 15]. In the mammalian brain, OT is also both a neurohormone and neurotransmitter [16]. It is structurally very similar to its sister peptide vasopressin, differing by only two amino acids in humans. OT is synthesized in distinct neurons in the paraventricular and supraoptic nucleii of the hypothalamus and released into portal circulation via hypothalamo-neurohypophyseal fibers terminating in the posterior pituitary and into specific brain regions such as the nucleus accumbens, and amygdala $[17,18]$ via axonal transport. In addition to its binding and subsequent action via the oxytocin receptor (OXTR), OT also has lower but functionally 
significant affinity for vasopressin receptors, including the AVP-1A (V1A) receptor (the AVPR most abundant in brain) and AVP1B receptors [19]. In fact, OT binding to AVP1AR can contribute to OT's CNS relevant effects [20], and sometimes, is solely responsible, [21, 22]. In clinical or preclinical studies related to SCZ spectrum disorders the relative role of OXTR versus AVPRs has not been well elucidated. Readers should take note, that the experimental effects of OT described in this lead article, may be mediated by OXTR, one of the AVPRs, or both.

In addition to its well-known action as a neurohormone, OT also acts as a peptide neurotransmitter in the brain. However, the mechanisms of its central action differ somewhat from that of classical neurotransmitters. For example, in contrast to classic neurotransmitters, OT produces its effects via both axonal release from parvocellular neurons in the hypothalamic paraventricular nucleus into specific brain regions as well as through somatodendritic release into the CSF and subsequent diffusion (volume effects) in the brain. Neuropeptides such as OT unlike neurotransmitters do not have a reuptake system and can produce variety of effects via short-range diffusion in CSF and extracellular fluid $[23,16]$. OT receptors have been localized to several areas associated with SCZ including subregions of the basal ganglia, central nucleus of the amygdala, substantia nigra, and lateral septal nucleus [24-26].

The functional significance of OXTRs was brought to light by [27] their discovery that the distribution and density of OXTRs in the ventral striatum (nucleus accumbens) contributed to contrasting social attachment styles (monogamous vs. promiscuous) in voles. This finding has significant translational relevance as differential distribution and density of OXTRs in reward relevant brain regions in humans may help to explain individual differences in social attachment behaviors. Dolan et al. using an oxytocin antagonist demonstrated that OT acts as a social reinforcement signal within the nucleus accumbens core in mice, where it elicits presynaptically expressed long-term depression of excitatory synaptic transmission in medium spiny neurons. This study also established a key role for serotonergic transmission via 5-HT1B receptors in the nucleus accumbens, in the processing of OT-mediated social reward [18].

Converging evidence suggests that OT interacts with several neurotransmitter systems in the brain including dopamine [28-30], glutamate [31-33] and serotonin [34] to produce some of its antipsychotic drug relevant behavioral effects. The preclinical studies supporting these interactions are reviewed elsewhere [57]. Clinical studies relevant to the potential role of OT in the etiology of SCZ are described in the next section.

\section{Endogenous OT and Schizophrenia}

Evidence for an inverse relationship between plasma OT (pOT) levels and symptom severity suggests that OT may contribute to the etiology of SCZ. For example, low pOT levels have been associated with more severe symptoms in all three domains of SCZ, although these findings have been most consistent for the negative symptoms and cognitive deficits. However, it is not completely clear if this relationship is causal, a consequence of the disease or a response to APD treatment. In addition, there is controversy regarding the relevance of 
peripheral OT to OT in the CNS. Some reports do not support CSF OT concentrations as related to pOT levels bringing into question the potential relevance of peripheral OT levels to the behaviors of interest [35, 36]. But see [37] and for reviews see [38, 23]. Of particular interest, Quintana et al. cite evidence that activation of OT receptors in the heart by peripheral OT can moderate the effects of intranasal OT on social behaviors. [39].

In regards to the positive symptoms, there have only been a few reports and the findings have not been completely consistent. For example, female patients who had less severe positive symptoms and overall pathology also had higher pOT levels ([40] (Table 1). In contrast, the same group reported more recently, that more severe positive symptoms were related to higher pOT [41].

As opposed to the positive symptoms, many studies have addressed the relationship between the severity of negative symptoms and pOT levels and they have consistently found an inverse relationship between the severity of negative symptoms and levels of pOT and OT levels in CSF cerebrospinal fluid. For example, Jobst et al. [42] and Sasamyama et al. [43] reported more severe negative symptoms were related to lower pOT and lower CSF OT levels, respectively. In a more recent study, Strauss et al found that the severity of asociality in patients with SCZ can be predicted by lower pOT levels [44]. Consistent with these findings, Keri et al. reported that flattened affect and social withdrawal may be associated with decreased trust-related OT levels in SCZ [45]. Several genetic studies have provided further support that the OT system may contribute to the negative symptoms of SCZ. For example, Souza et al. 2010 [46] reported nominal association with the negative symptoms in patients with SCZ and an OT gene variant (rs2740204). More recently, Montag et al. detected significant association with negative symptom scores (PANSS) and OXTR variants rs53576 and rs237885 [47]. Furthermore, Haram et al. [48] found significant association between emotional withdrawal and the OXTR gene variant rs53576. It is very compelling that two independent genetic studies found significant association between negative symptoms and the same OXTR gene variant (rs53576).

Relevant to cognition, higher pOT levels have been associated with enhanced social cognition including more prosocial behavior in males and females [40], superior emotion recognition [49], perception of faces as happier by female SCZ and controls [50]. Also consistent with a role for endogenous OT in social cognition, higher pOT levels in patients with SCZ were associated with more avoidance of angry faces in an Approach-Avoidance task [51], better emotion recognition in controls and SCZ (females only) [52] and more accurate encoding of socially relevant information in SCZ [53]. Although they did not detect differences in pOT levels between SCZ and controls, Frost et al. reported that in addition to social cognition, superior processing speed and working memory were also associated with higher levels of pOT [54]. However, Rubin et al. reported that OT levels in patients with SCZ were not related to clinical symptoms or cognition [55, 41].

Findings from genetic studies have also consistently detected endogenous OT as a potential contributor to social cognitive deficits. In this respect, worse social perception, mentalizing and poorer performance on a social cognition index in patients with SCZ were significantly 
associated with OXTR (rs2268493) variant [56] and the OXTR variant rs22544298 was significantly associated with empathic concern [57].

\section{Preclinical Models of OT and Schizophrenia}

Animal models of relevance to SCZ have limitations in their ability to model the disorder, especially the positive symptoms such as hallucinations and delusions. However, animal models have been an invaluable tool for identifying novel compounds with APD potential. In addition, animal models allow investigators to utilize powerful techniques that would be too invasive (e.g., in vivo brain sampling) in humans. A variety of animal models have been utilized to investigate the potential therapeutic-like effects of OT against all three symptom domains of SCZ. These studies have been reviewed elsewhere. Please see [58] for a recent review.

\section{Therapeutic Effects of Exogenous OT on Schizophrenia}

Initially a potential role for OT in alleviating the positive symptoms of SCZ was supported by the converging preclinical evidence that OT may counteract central hyperdopaminegia and hypoglutamatergia $[59,31]$. In subsequent studies in healthy subjects administration of a single intranasal (IN) dose of OT was reported to enhance trust of strangers by healthy subjects $[60,61]$.

More recently, several small clinical trials designed primarily to investigate the potential of IN OT as to reduce SCZ symptoms have been published. However, each of these studies has investigated IN OT as add-on to standard APDs or non-pharmacological treatments aimed at improving social behavior. Thus, the gold standard approach to assessing the efficacy of a putative drug, a monotherapy randomized, controlled clinical trial has yet to be conducted, limiting the ability of the field to truly determine the inherent therapeutic properties of OT for SCZ.

To date, four small clinical trials designed primarily to investigate the potential of IN OT as an adjunct medication to stable doses of APDs, to further attenuate psychosis in SCZ, have been published (see Table 2 for a summary of OT clinical trials in SCZ). In the initial clinical trial, Feifel et al. performed a clinical proof-of-concept study of the therapeutic potential of OT by employing a randomized double blind placebo-controlled crossover design. IN OT given twice daily to patients with SCZ for three weeks significantly decreased positive subscale scores on the Positive and Negative Symptoms Scale (PANSS) [62]. The clinical significance of their findings was demonstrated by significant improvement in the Clinical Global Impression (CGI) scores. In addition, OT improved learning (California Verbal Learning Test) but not working memory (Letter Number Sequence) after 3 weeks of treatment [63]. In contrast, Michalopoulou et al. 2015 recently reported that a single dose of OT improved the "executive" component of working memory in patients with SCZ [64].

In a subsequent clinical trial by Pedersen et al [65], twice daily IN OT given to patients with SCZ for 2 weeks significantly reduced the PANSS positive subscale scores compared to IN placebo and produced a nearly significant reduction in the PANSS negative subscale ( $\mathrm{P}<$ 0.08). This treatment regimen also improved cognitive deficits, i.e., identification of second 
false beliefs and trends toward significant improvement in accurate recognition of deception and rating untrustworthy faces as trustworthy (Brune task). Modabbernia, et al. [66], In the largest human trial to date, reported that administration of twice daily IN OT to SCZ for eight weeks significantly improved PANSS total, positive and negative sub scores as early as 4 weeks after the initiation of OT treatment.

In the fourth trial, Lee, at al. [67] did not detect a significant change in Brief Psychiatric Rating Scale (BPRS) in patients with SCZ after administration of twice daily IN OT for three weeks. These negative findings, which were not consistent with the first three clinical trials could be related to the use of the BPRS. The overall score of this 18-item scale represents a summation of various aspects of psychosis. The 30-item PANSS, considered the gold standard in SCZ research, was used in the three studies reporting positive findings. In contrast to the BPRS, the PANSS items are readily categorized into separate subscores for positive, negative and general symptoms of SCZ. In contrast to their negative findings on the therapeutic effects of OT on positive symptoms, Lee et al. found that negative symptoms improved in a small group of patients, 3 weeks after the start of OT treatment. Neither Lee et al. nor Modabbernia et al. investigated the effects of OT on cognitive deficits.

Three additional clinical trials also measured changes in psychosis but as a secondary measure. These studies were designed to investigate the effects of IN OT on social cognition in SCZ. In the first of these studies, Gibson, et al. [68] found no improvement in PANSS positive scale scores after six weeks of twice daily IN OT compared to IN placebo. On the other hand, OT reduced fear recognition and the perspective-taking component of empathy (ER-40), as well as, PANSS negative subscale scores.

Based on converging evidence consistent with OT's potential as a "cognitive/plasticity enhancer," [69], the benefits of OT added to a potent psychosocial treatment has been investigated by a couple of research teams. For instance, Cacciotti-Salja, et al. reported adding twice daily IN OT or IN placebo to six weeks of social cognitive training in patients with early psychosis did not increase the positive effects of SCT beyond the effects of placebo. They also found no improvement of positive symptoms (measured with the Scale for the Assessment of Positive Symptoms, SAPS) beyond the social cognition training alone [70] and daily OT added to SCT did not add to the improvement in SANS scores after placebo. However, there was a positive correlation between the reduction of negative symptoms as measured by the Scale for Assessment of Negative Symptoms (SANS) and the volume of IN OT (total number of OT IN treatments) but not placebo, administered by patients with SCZ. In the second study, Davis et al. reported that OT given just before twice weekly sessions of a 6-week social cognitive training enhanced social cognitive benefits greater than placebo and this improvement in empathic accuracy lasted at least one month. However, they did not detect improvement in BPRS [71] or negative symptoms (CAINS) beyond those produced by SCT alone. As in all the studies reviewed here, these contrasting results may be due to different dosage or duration of OT treatment employed (see study details in Table 2), highlighting the great need for more studies aimed at identifying the optimal dose and time course of OT treatment. 
In addition, a single dose of IN OT has been reported to enhance performance of patients with SCZ on many social cognitive tasks including deception, sarcasm, recognition of emotion, and empathy [72-77]. The effects of IN OT on social cognition in healthy subjects are reviewed in Evans et al. [78]. In these studies, a single administration of IN OT consistently enhanced the processing of social stimuli.

Recently, Shin et al. [79] in the first report of OT effects on neural activity associated with social cognition (facial emotion recognition) in SCZ found that a single dose of IN OT increased activity (FMRI) for happy faces while decreasing amygdala activity for fearful faces. These results are consistent with many other reports of alterations in amygdala activity in normal controls during emotional recognition tasks [80].

In summary, the robust ability of OT to facilitate trust toward strangers provides a potential mechanism for its therapeutic action on paranoid delusions (positive symptom). OT reduced positive symptoms in three out of four clinical studies designed to measure the effects of IN OT on psychosis in SCZ. However, OT-improvement of positive symptoms was not detected in three other studies aimed at testing the ability of OT to enhance social cognitive training or to improve social cognition. Importantly, six of the seven clinical studies that measured the effects of OT on negative symptoms provided evidence that OT may reduce negative symptoms. In the lone study that did not provide such evidence, Davis et al. [71], the lack of an effect of OT on the negative symptoms could have been due to the minimal OT treatment regimen ( 2 times per week), in contrast to the daily OT treatment regimen used in the other six studies. It is noteworthy that in contrast with animal studies [81-84], where chronic OT administration produced either no benefit or exacerbation of social interaction in rodents, these clinical studies reveal very promising effects of chronic daily OT on negative symptoms. Finally, both acute and chronic OT administration has consistently improved social cognition in both controls and patients with SCZ.

\section{Conclusions}

Patients with SCZ desperately need more effective treatments, especially for the negative symptoms and cognitive deficits that are incompletely treated by current APDs. The findings described in this review from the recent small randomized double blind placebo controlled add-on clinical trials and studies of the endogenous OT system in patients with SCZ are encouraging, though not completely consistent. Together, they suggest that OT may reduce the currently treatment resistant debilitating negative symptoms and social cognitive deficits, as well as the more treatment responsive positive symptoms. IN OT produced no significant adverse effects and was well tolerated across clinical studies. Despite these encouraging preliminary findings, many issues, still need to be addressed while optimizing OT or OTmimetics to alleviate symptoms of SCZ-spectrum disorders.

The extant clinical trials collectively do not represent an adequate test of the therapeutic potential of OT for SCZ. For example, each trial has been small and only one dose of OT (range $48-80 \mathrm{IU} /$ day) was administered as an adjunct therapy to already stable regimens of APDs. Therefore, the optimal time course, therapeutic OT dose, and dosing regimen for optimal treatment of all three clinical domains of SCZ has yet to be identified. 
Significant limitations are inherent to add-on trials (see $[85,86]$ ), and especially problematic is their inability to test the hypothesis that the added drug is an effective treatment for the clinical disorder of interest. Add-on trials are limited to testing whether the add-on drug plus the primary drug are more effective than the primary drug alone. Of particular concern, were studies in which OT was given as an adjunct to non-pharmacological interventions such as social cognition training, while patients were also on stable regimens of APDs, making it even more difficult to detect a therapeutic effect of OT.

The inclusion criteria, which requires patients exhibit significant symptoms (i.e., PANSS score) after being stabilized on an established APD is another serious limitation of the addon study designs for IN OT in SCZ. These subjects at best have had an incomplete response to the primary treatment, i.e. APDs, and at worst, no response to the primary treatment. The incomplete responders will have decreased symptoms at baseline and, therefore, a limited range of symptoms to exhibit improvement to the add-on therapy compared to untreated patients (celling effect). As non-responders are often treatment resistent they are less likely to respond to any drug treatment compared to most patients with SCZ. As expected, drugs that have been tested as both add-ons and as a monotherapy, reveal less therapeutic effect sizes as add-on medications (e.g., [87]).

The gold standard approach to assessing the efficacy of a putative drug, a monotherapy randomized, placebo-controlled clinical trial has yet to be conducted, limiting the ability of the field to truly determine the inherent therapeutic properties of OT for SCZ. The optimal clinical utility of OT for SCZ may ultimately be as an adjunct to conventional APDs as it may not possess sufficient efficacy on some of the core-features of this disorder (e.g., positive symptoms) to be used as a monotherapy alternative to conventional APDs. However in order to effectively characterize the inherent potential clinical effects of OT for the various clinical features of SCZ, a monotherapy trial of OT in SCZ needs to be conducted.

Although it would be optimal to perform OT monotherapy clinical trials designed to investigate the therapeutic efficacy of OT against SCZ, it is unlikely that many IRBs will approve outpatient placebo-controlled monotherapy trials of an investigational drug in subjects with SCZ. Regarding OT, IRBs are especially cautious since its mechanism of action remains to be fully elucidated and APD monotherapy trials usually require hospitalization of subjects, at least during the initial study phase and during the drug washout [88]. In this respect, gaps in our knowledge about the drug properties of OT, described above and in more detail in a previous paper [89], should be elucidated before conducting a monotherapy trial.

An adequately powered test of the efficacy of OT as an adjunct to APDs would require a larger sample size than an OT monotherapy trial due to the reduced effect size associated with add-on studies. Considering the previously described limitations inherent in their addon design, and administration of only one OT dose and small sample sizes, it is very promising that 3 out of 4 clinical trials designed to test the anti-psychotic effects of OT (versus social cognition effects) found that OT exhibited therapeutic efficacy against the positive symptoms of SCZ [62, 65-67]. It is also not very surprising that three recent studies designed to specifically investigate the therapeutic effects of OT on social cognition did not 
detect improvement in positive symptoms or negative symptoms. The most encouraging results suggest that OT consistently had therapeutic effects on negative symptoms and cognitive deficits, the symptoms most in need of effective treatments. In this respect, 6 out of 7 small clinical trials found evidence that OT had some therapeutic efficacy against the negative symptoms and social cognitive deficits. The lone study that failed to detect any therapeutic effects of OT against cognitive deficits was unable to detect an OT improvement in cognitive deficits beyond the improvement produced by social cognition training alone.

Therapeutic effects of OT consistent with some of the findings reviewed here, could provide much needed hope to patients with SCZ and their families that OT may provide relief especially from the poorly treated and debilitating negative symptoms and cognitive deficits. The effective treatment of these symptoms by OT would likely lead to improvement in the poor prognosis characteristic of this disorder, hopefully allowing those suffering from SCZ to lead more fulfilling lives.

\section{Acknowledgments}

DF and PDS are partially funded by NIMH (RO1 MH103421-01A1).

\section{References}

1. Young J, Geyer M. Developing treatments for cognitive deficits in schizophrenia: The challenge of translation. J Psychopharmacol. 2015; 29(2):178-96. DOI: 10.1177/0269881114555252 [PubMed: 25516372]

2. Feifel, D., Shilling, PD. Modeling schizophrenia in animals. In: Conn, MP., editor. Animal Models for the Study of Human Disease. New York: Elsevier; 2013. p. 727-48.

3. Miyamoto S, Miyake N, Jarskog LF, Fleischhacker WW, Lieberman JA. Pharmacological treatment of schizophrenia: a critical review of the pharmacology and clinical effects of current and future therapeutic agents. Mol Psychiatry. 2012; 17(12):1206-27. DOI: 10.1038/mp.2012.47 [PubMed: 22584864]

4. Weinberger DR, Gallhofer B. Cognitive function in schizophrenia. Int Clin Psychopharmacol. 1997; 12(Suppl 4):S29-36.

5. Minassian A, Young JW. Evaluation of the clinical efficacy of asenapine in schizophrenia. Expert Opin Pharmacother. 2010; 11(12):2107-15. DOI: 10.1517/14656566.2010.506188 [PubMed: 20642375]

6. Kuroki T, Nagao N, Nakahara T. Neuropharmacology of second-generation antipsychotic drugs: a validity of the serotonin-dopamine hypothesis. Prog Brain Res. 2008; 172:199-212. S0079-6123(08)00910-2 [pii]. DOI: 10.1016/S0079-6123(08)00910-2 [PubMed: 18772034]

7. Krakowski MI, Czobor P, Nolan KA. Atypical antipsychotics, neurocognitive deficits, and aggression in schizophrenic patients. J Clin Psychopharmacol. 2008; 28(5):485-93. [pii]. DOI: 10.1097/JCP.0b013e3181855cd600004714-200810000-00003 [PubMed: 18794642]

8. McGurk SR, Lee MA, Jayathilake K, Meltzer HY. Cognitive effects of olanzapine treatment in schizophrenia. MedGenMed. 2004; 6(2):27. 474626 [pii].

9. Carpenter WT, Koenig JI. The evolution of drug development in schizophrenia: past issues and future opportunities. Neuropsychopharmacology. 2008; 33(9):2061-79. 1301639 [pii]. DOI: 10.1038/sj.npp.1301639 [PubMed: 18046305]

10. Kirkpatrick B, Fenton WS, Carpenter WT Jr, Marder SR. The NIMH-MATRICS consensus statement on negative symptoms. Schizophr Bull. 2006; 32(2):214-9. sbj053 [pii]. DOI: 10.1093/ schbul/sbj053 [PubMed: 16481659]

11. Sarnyai Z, Kovacs GL. Oxytocin in learning and addiction: From early discoveries to the present. Pharmacol Biochem Behav. 2014; 119:3-9. DOI: 10.1016/j.pbb.2013.11.019 [PubMed: 24280016] 
12. Donaldson ZR, Young LJ. Oxytocin, vasopressin, and the neurogenetics of sociality. Science. 2008; 322(5903):900-4. DOI: 10.1126/science.1158668 [PubMed: 18988842]

13. Gimpl G, Fahrenholz F. The oxytocin receptor system: structure, function, and regulation. Physiol Rev. 2001; 81(2):629-83. [PubMed: 11274341]

14. Sogolow SR. An historical review of the use of oxytocin prior to delivery. Obstet Gynecol Surv. 1966; 21(2):155-72. [PubMed: 5324901]

15. Uvnas-Moberg K, Eriksson M. Breastfeeding: physiological, endocrine and behavioural adaptations caused by oxytocin and local neurogenic activity in the nipple and mammary gland. Acta Paediatr. 1996; 85(5):525-30. [PubMed: 8827091]

16. Landgraf R, Neumann ID. Vasopressin and oxytocin release within the brain: a dynamic concept of multiple and variable modes of neuropeptide communication. Front Neuroendocrinol. 2004; 25(34):150-76. S0091302204000056 [pii]. DOI: 10.1016/j.yfrne.2004.05.001 [PubMed: 15589267]

17. Macdonald K, Feifel D. Oxytocin in schizophrenia: a review of evidence for its therapeutic effects. Acta Neuropsychiatr. 2012; 24(3):130-46. DOI: 10.1111/j.1601-5215.2011.00634.x [PubMed: 22736892]

18. Dolen G, Darvishzadeh A, Huang KW, Malenka RC. Social reward requires coordinated activity of nucleus accumbens oxytocin and serotonin. Nature. 2013; 501(7466):179-84. DOI: 10.1038/ nature 12518 [PubMed: 24025838]

19. Manning M, Misicka A, Olma A, Bankowski K, Stoev S, Chini B, et al. Oxytocin and vasopressin agonists and antagonists as research tools and potential therapeutics. J Neuroendocrinol. 2012; 24(4):609-28. DOI: 10.1111/j.1365-2826.2012.02303.x [PubMed: 22375852]

20. Sala M, Braida D, Lentini D, Busnelli M, Bulgheroni E, Capurro V, et al. Pharmacologic rescue of impaired cognitive flexibility, social deficits, increased aggression, and seizure susceptibility in oxytocin receptor null mice: a neurobehavioral model of autism. Biol Psychiatry. 2011; 69(9):87582. S0006-3223(10)01314-4 [pii]. DOI: 10.1016/j.biopsych.2010.12.022 [PubMed: 21306704]

21. Schorscher-Petcu A, Sotocinal S, Ciura S, Dupre A, Ritchie J, Sorge RE, et al. Oxytocin-induced analgesia and scratching are mediated by the vasopressin-1A receptor in the mouse. J Neurosci. 2010; 30(24):8274-84. DOI: 10.1523/JNEUROSCI.1594-10.2010 [PubMed: 20554879]

22. Song Z, McCann KE, McNeill JKt, Larkin TE 2nd, Huhman KL, Albers HE. Oxytocin induces social communication by activating arginine-vasopressin V1a receptors and not oxytocin receptors. Psychoneuroendocrinology. 2014; 50C:14-9. DOI: 10.1016/j.psyneuen.2014.08.005

23. Veening JG, de Jong T, Barendregt HP. Oxytocin-messages via the cerebrospinal fluid: behavioral effects; a review. Physiol Behav. 2010; 101(2):193-210. DOI: 10.1016/j.physbeh.2010.05.004 [PubMed: 20493198]

24. Loup F, Tribollet E, Dubois-Dauphin M, Dreifuss JJ. Localization of high-affinity binding sites for oxytocin and vasopressin in the human brain. An autoradiographic study. Brain Res. 1991; 555(2): 220-32. [PubMed: 1657300]

25. Loup F, Tribollet E, Dubois-Dauphin M, Pizzolato G, Dreifuss JJ. Localization of oxytocin binding sites in the human brainstem and upper spinal cord: an autoradiographic study. Brain Res. 1989; 500(1-2):223-30. [PubMed: 2557960]

26. Tribollet E, Dubois-Dauphin M, Dreifuss JJ, Barberis C, Jard S. Oxytocin receptors in the central nervous system. Distribution, development, and species differences. Ann N Y Acad Sci. 1992; 652:29-38. [PubMed: 1320828]

27. Insel TR, Young L, Wang Z. Molecular aspects of monogamy. Ann N Y Acad Sci. 1997; 807:30216. [PubMed: 9071359]

28. Shahrokh DK, Zhang TY, Diorio J, Gratton A, Meaney MJ. Oxytocin-dopamine interactions mediate variations in maternal behavior in the rat. Endocrinology. 2010; 151(5):2276-86. DOI: 10.1210/en.2009-1271 [PubMed: 20228171]

29. Baskerville TA, Douglas AJ. Dopamine and oxytocin interactions underlying behaviors: potential contributions to behavioral disorders. CNS Neurosci Ther. 2010; 16(3):e92-123. DOI: 10.1111/j. 1755-5949.2010.00154.x [PubMed: 20557568]

30. Succu S, Sanna F, Melis T, Boi A, Argiolas A, Melis MR. Stimulation of dopamine receptors in the paraventricular nucleus of the hypothalamus of male rats induces penile erection and increases extra-cellular dopamine in the nucleus accumbens: Involvement of central oxytocin. 
Neuropharmacology. 2007; 52(3):1034-43. DOI: 10.1016/j.neuropharm.2006.10.019 [PubMed: 17164075]

31. Caldwell HK, Stephens SL, Young WS 3rd. Oxytocin as a natural antipsychotic: a study using oxytocin knockout mice. Mol Psychiatry. 2009; 14(2):190-6. 4002150 [pii]. DOI: 10.1038/sj.mp. 4002150 [PubMed: 18227836]

32. Hrabovszky E, Liposits Z. Novel aspects of glutamatergic signalling in the neuroendocrine system. J Neuroendocrinol. 2008; 20(6):743-51. DOI: 10.1111/j.1365-2826.2008.01719.x [PubMed: 18601697]

33. Ninan I. Oxytocin suppresses basal glutamatergic transmission but facilitates activity-dependent synaptic potentiation in the medial prefrontal cortex. J Neurochem. 2011; 119(2):324-31. DOI: 10.1111/j.1471-4159.2011.07430.x [PubMed: 21848811]

34. Emiliano AB, Cruz T, Pannoni V, Fudge JL. The interface of oxytocin-labeled cells and serotonin transporter-containing fibers in the primate hypothalamus: a substrate for SSRIs therapeutic effects? Neuropsychopharmacology. 2007; 32(5):977-88. DOI: 10.1038/sj.npp.1301206 [PubMed: 17035935]

35. Kagerbauer SM, Martin J, Schuster T, Blobner M, Kochs EF, Landgraf R. Plasma oxytocin and vasopressin do not predict neuropeptide concentrations in human cerebrospinal fluid. J Neuroendocrinol. 2013; 25(7):668-73. DOI: 10.1111/jne.12038 [PubMed: 23574490]

36. Takagi T, Tanizawa O, Otsuki Y, Sugita N, Haruta M, Yamaji K. Oxytocin in the cerebrospinal fluid and plasma of pregnant and nonpregnant subjects. Horm Metab Res. 1985; 17(6):308-10. DOI: 10.1055/s-2007-1013526 [PubMed: 4018719]

37. Carson DS, Berquist SW, Trujillo TH, Garner JP, Hannah SL, Hyde SA, et al. Cerebrospinal fluid and plasma oxytocin concentrations are positively correlated and negatively predict anxiety in children. Mol Psychiatry. 2015; 20(9):1085-90. DOI: 10.1038/mp.2014.132 [PubMed: 25349162]

38. Veenema AH, Neumann ID. Central vasopressin and oxytocin release: regulation of complex social behaviours. Prog Brain Res. 2008; 170:261-76. DOI: 10.1016/S0079-6123(08)00422-6 [PubMed: 18655888]

39. Quintana DS, Kemp AH, Alvares GA, Guastella AJ. A role for autonomic cardiac control in the effects of oxytocin on social behavior and psychiatric illness. Front Neurosci. 2013; 7:48.doi: 10.3389/fnins.2013.00048 [PubMed: 23565075]

40. Rubin LH, Carter CS, Drogos L, Pournajafi-Nazarloo H, Sweeney JA, Maki PM. Peripheral oxytocin is associated with reduced symptom severity in schizophrenia. Schizophr Res. 2010; 124(1-3):13-21. DOI: 10.1016/j.schres.2010.09.014 [PubMed: 20947304]

41. Rubin LH, Carter CS, Bishop JR, Pournajafi-Nazarloo H, Drogos LL, Hill SK, et al. Reduced levels of vasopressin and reduced behavioral modulation of oxytocin in psychotic disorders. Schizophr Bull. 2014; 40(6):1374-84. DOI: 10.1093/schbul/sbu027 [PubMed: 24619535]

42. Jobst A, Dehning S, Ruf S, Notz T, Buchheim A, Henning-Fast K, et al. Oxytocin and vasopressin levels are decreased in the plasma of male schizophrenia patients. Acta Neuropsychiatr. 2014; 26(6):347-55. DOI: 10.1017/neu.2014.20 [PubMed: 25288094]

43. Sasayama D, Hattori K, Teraishi T, Hori H, Ota M, Yoshida S, et al. Negative correlation between cerebrospinal fluid oxytocin levels and negative symptoms of male patients with schizophrenia. Schizophr Res. 2012; 139(1-3):201-6. DOI: 10.1016/j.schres.2012.06.016 [PubMed: 22742979]

44. Strauss GP, Keller WR, Koenig JI, Gold JM, Ossenfort KL, Buchanan RW. Plasma oxytocin levels predict olfactory identification and negative symptoms in individuals with schizophrenia. Schizophr Res. 2015; 162(1-3):57-61. DOI: 10.1016/j.schres.2014.12.023 [PubMed: 25583247]

45. Keri S, Kiss I, Kelemen O. Sharing secrets: oxytocin and trust in schizophrenia. Soc Neurosci. 2009; 4(4):287-93. 795449706 [pii]. DOI: 10.1080/17470910802319710 [PubMed: 18671168]

46. Souza RP, de Luca V, Meltzer HY, Lieberman JA, Kennedy JL. Schizophrenia severity and clozapine treatment outcome association with oxytocinergic genes. Int J Neuropsychopharmacol. 2010; 13(6):793-8. S1461145710000167 [pii]. DOI: 10.1017/S1461145710000167 [PubMed: 20196918]

47. Montag C, Brockmann EM, Bayerl M, Rujescu D, Muller DJ, Gallinat J. Oxytocin and oxytocin receptor gene polymorphisms and risk for schizophrenia: a case-control study. World J Biol Psychiatry. 2013; 14(7):500-8. DOI: 10.3109/15622975.2012.677547 [PubMed: 22651577] 
48. Haram M, Tesli M, Bettella F, Djurovic S, Andreassen OA, Melle I. Association between Genetic Variation in the Oxytocin Receptor Gene and Emotional Withdrawal, but not between Oxytocin Pathway Genes and Diagnosis in Psychotic Disorders. Front Hum Neurosci. 2015; 9:9.doi: 10.3389/fnhum.2015.00009 [PubMed: 25667571]

49. Goldman M, Marlow-O'Connor M, Torres I, Carter CS. Diminished plasma oxytocin in schizophrenic patients with neuroendocrine dysfunction and emotional deficits. Schizophr Res. 2008; 98(1-3):247-55. S0920-9964(07)00427-6 [pii]. DOI: 10.1016/j.schres.2007.09.019 [PubMed: 17961988]

50. Rubin LH, Carter CS, Drogos L, Jamadar R, Pournajafi-Nazarloo H, Sweeney JA, et al. Sexspecific associations between peripheral oxytocin and emotion perception in schizophrenia. Schizophr Res. 2011; 130(1-3):266-70. DOI: 10.1016/j.schres.2011.06.002 [PubMed: 21684122]

51. Brown EC, Tas C, Kuzu D, Esen-Danaci A, Roelofs K, Brune M. Social approach and avoidance behaviour for negative emotions is modulated by endogenous oxytocin and paranoia in schizophrenia. Psychiatry Res. 2014; 219(3):436-42. DOI: 10.1016/j.psychres.2014.06.038 [PubMed: 25048758]

52. Strauss GP, Keller WR, Koenig JI, Sullivan SK, Gold JM, Buchanan RW. Endogenous oxytocin levels are associated with the perception of emotion in dynamic body expressions in schizophrenia. Schizophr Res. 2015; 162(1-3):52-6. DOI: 10.1016/j.schres.2015.01.022 [PubMed: 25620121]

53. Strauss GP, Keller WR, Koenig JI, Gold JM, Frost KH, Buchanan RW. Plasma oxytocin levels predict social cue recognition in individuals with schizophrenia. Schizophr Res. 2015; doi: 10.1016/j.schres.2015.01.034

54. Frost K, Keller W, Buchanan R, Gold J, Koenig J, Ossenfort K, et al. C-14Plasma Oxytocin Levels are Associated with Impaired Social Cognition and Neurocognition in Schizophrenia. Archives of clinical neuropsychology: the official journal of the National Academy of Neuropsychologists. 2014; 29(6):577-8. DOI: 10.1093/arclin/acu038.195

55. Rubin LH, Carter CS, Bishop JR, Pournajafi-Nazarloo H, Harris MS, Hill SK, et al. Peripheral vasopressin but not oxytocin relates to severity of acute psychosis in women with acutely-ill untreated first-episode psychosis. Schizophr Res. 2013; 146(1-3):138-43. DOI: 10.1016/j.schres. 2013.01.019 [PubMed: 23465965]

56. Davis MC, Horan WP, Nurmi EL, Rizzo S, Li W, Sugar CA, et al. Associations between oxytocin receptor genotypes and social cognitive performance in individuals with schizophrenia. Schizophr Res. 2014; 159(2-3):353-7. DOI: 10.1016/j.schres.2014.09.006 [PubMed: 25244972]

57. Montag C, Brockmann EM, Lehmann A, Muller DJ, Rujescu D, Gallinat J. Association between oxytocin receptor gene polymorphisms and self-rated 'empathic concern' in schizophrenia. PLoS One. 2012; 7(12):e51882.doi: 10.1371/journal.pone.0051882 [PubMed: 23284802]

58. Feifel D, Shilling PD, Macdonald K. A review of oxytocin's effects on the positive, negative, and cognitive domains of schizophrenia. Biological Psychiatry. 2015 In Press.

59. Feifel D, Reza T. Oxytocin modulates psychotomimetic-induced deficits in sensorimotor gating. Psychopharmacology. 1999; 141(1):93-8. [PubMed: 9952070]

60. Kosfeld M, Heinrichs M, Zak PJ, Fischbacher U, Fehr E. Oxytocin increases trust in humans. Nature. 2005; 435(7042):673-6. DOI: 10.1038/nature03701 [PubMed: 15931222]

61. Baumgartner T, Heinrichs M, Vonlanthen A, Fischbacher U, Fehr E. Oxytocin shapes the neural circuitry of trust and trust adaptation in humans. Neuron. 2008; 58(4):639-50. DOI: 10.1016/ j.neuron.2008.04.009 [PubMed: 18498743]

62. Feifel D, Macdonald K, Nguyen A, Cobb P, Warlan H, Galangue B, et al. Adjunctive intranasal oxytocin reduces symptoms in schizophrenia patients. Biol Psychiatry. 2010; 68(7):678-80. DOI: 10.1016/j.biopsych.2010.04.039 [PubMed: 20615494]

63. Feifel D, Macdonald K, Cobb P, Minassian A. Adjunctive intranasal oxytocin improves verbal memory in people with schizophrenia. Schizophr Res. 2012; 139(1-3):207-10. DOI: 10.1016/ j.schres.2012.05.018 [PubMed: 22682705]

64. Michalopoulou PG, Averbeck BB, Kalpakidou AK, Evans S, Bobin T, Kapur S, et al. The effects of a single dose of oxytocin on working memory in schizophrenia. Schizophr Res. 2015; doi: 10.1016/j.schres.2014.12.029 
65. Pedersen CA, Gibson CM, Rau SW, Salimi K, Smedley KL, Casey RL, et al. Intranasal oxytocin reduces psychotic symptoms and improves Theory of Mind and social perception in schizophrenia. Schizophr Res. 2011; 132(1):50-3. S0920-9964(11)00425-7 [pii]. DOI: 10.1016/j.schres. 2011.07.027 [PubMed: 21840177]

66. Modabbernia A, Rezaei F, Salehi B, Jafarinia M, Ashrafi M, Tabrizi M, et al. Intranasal oxytocin as an adjunct to risperidone in patients with schizophrenia: an 8-week, randomized, double-blind, placebo-controlled study. CNS Drugs. 2013; 27(1):57-65. DOI: 10.1007/s40263-012-0022-1 [PubMed: 23233269]

67. Lee MR, Wehring HJ, McMahon RP, Linthicum J, Cascella N, Liu F, et al. Effects of adjunctive intranasal oxytocin on olfactory identification and clinical symptoms in schizophrenia: results from a randomized double blind placebo controlled pilot study. Schizophr Res. 2013; 145(1-3): 110-5. DOI: 10.1016/j.schres.2013.01.001 [PubMed: 23415472]

68. Gibson CM, Penn DL, Smedley KL, Leserman J, Elliott T, Pedersen CA. A pilot six-week randomized controlled trial of oxytocin on social cognition and social skills in schizophrenia. Schizophr Res. 2014; 156(2-3):261-5. DOI: 10.1016/j.schres.2014.04.009 [PubMed: 24799299]

69. Singewald N, Schmuckermair C, Whittle N, Holmes A, Ressler KJ. Pharmacology of cognitive enhancers for exposure-based therapy of fear, anxiety and trauma-related disorders. Pharmacol Ther. 2014; doi: 10.1016/j.pharmthera.2014.12.004

70. Cacciotti-Saija C, Langdon R, Ward PB, Hickie IB, Scott EM, Naismith SL, et al. A Double-blind Randomized Controlled Trial of Oxytocin Nasal Spray and Social Cognition Training for Young People With Early Psychosis. Schizophr Bull. 2014; doi: 10.1093/schbul/sbu094

71. Davis MC, Green MF, Lee J, Horan WP, Senturk D, Clarke AD, et al. Oxytocin-Augmented Social Cognitive Skills Training in Schizophrenia. Neuropsychopharmacology. 2014; doi: 10.1038/npp. 2014.68

72. Averbeck BB, Bobin T, Evans S, Shergill SS. Emotion recognition and oxytocin in patients with schizophrenia. Psychol Med. 2011; :1-8. S0033291711001413 [pii]. DOI: 10.1017/ S0033291711001413

73. Goldman MB, Gomes AM, Carter CS, Lee R. Divergent effects of two different doses of intranasal oxytocin on facial affect discrimination in schizophrenic patients with and without polydipsia. Psychopharmacology (Berl). 2011; 216(1):101-10. DOI: 10.1007/s00213-011-2193-8 [PubMed: 21301811]

74. Fischer-Shofty M, Brune M, Ebert A, Shefet D, Levkovitz Y, Shamay-Tsoory SG. Improving social perception in schizophrenia: the role of oxytocin. Schizophr Res. 2013; 146(1-3):357-62. DOI: 10.1016/j.schres.2013.01.006 [PubMed: 23433504]

75. Davis MC, Lee J, Horan WP, Clarke AD, McGee MR, Green MF, et al. Effects of single dose intranasal oxytocin on social cognition in schizophrenia. Schizophr Res. 2013; 147(2-3):393-7. DOI: 10.1016/j.schres.2013.04.023 [PubMed: 23676253]

76. Woolley JD, Chuang B, Lam O, Lai W, O'Donovan A, Rankin KP, et al. Oxytocin administration enhances controlled social cognition in patients with schizophrenia. Psychoneuroendocrinology. 2014; 47:116-25. DOI: 10.1016/j.psyneuen.2014.04.024 [PubMed: 25001961]

77. Guastella AJ, Ward PB, Hickie IB, Shahrestani S, Hodge MA, Scott EM, et al. A single dose of oxytocin nasal spray improves higher-order social cognition in schizophrenia. Schizophr Res. 2015; doi: 10.1016/j.schres.2015.06.005

78. Evans SL, Dal Monte O, Noble P, Averbeck BB. Intranasal oxytocin effects on social cognition: a critique. Brain Res. 2014; 1580:69-77. DOI: 10.1016/j.brainres.2013.11.008 [PubMed: 24239931]

79. Shin NY, Park HY, Jung WH, Park JW, Yun JY, Jang JH, et al. Effects of Oxytocin on Neural Response to Facial Expressions in Patients with Schizophrenia. Neuropsychopharmacology. 2015; doi: 10.1038/npp.2015.41

80. Wigton R, Radua J, Allen P, Averbeck B, Meyer-Lindenberg A, McGuire P, et al. Neurophysiological effects of acute oxytocin administration: systematic review and meta-analysis of placebo-controlled imaging studies. J Psychiatry Neurosci. 2015; 40(1):E1-E22. [PubMed: 25520163] 
81. Bales KL, Solomon M, Jacob S, Crawley JN, Silverman JL, Larke RH, et al. Long-term exposure to intranasal oxytocin in a mouse autism model. Translational psychiatry. 2014; 4:e480.doi: 10.1038/tp.2014.117 [PubMed: 25386957]

82. Bales KL, Perkeybile AM, Conley OG, Lee MH, Guoynes CD, Downing GM, et al. Chronic intranasal oxytocin causes long-term impairments in partner preference formation in male prairie voles. Biol Psychiatry. 2013; 74(3):180-8. DOI: 10.1016/j.biopsych.2012.08.025 [PubMed: 23079235]

83. Huang H, Michetti C, Busnelli M, Manago F, Sannino S, Scheggia D, et al. Chronic and acute intranasal oxytocin produce divergent social effects in mice. Neuropsychopharmacology. 2014; 39(5):1102-14. DOI: 10.1038/npp.2013.310 [PubMed: 24190025]

84. Rault JL, Carter CS, Garner JP, Marchant-Forde JN, Richert BT, Lay DC Jr. Repeated intranasal oxytocin administration in early life dysregulates the HPA axis and alters social behavior. Physiol Behav. 2013; 112-113:40-8. DOI: 10.1016/j.physbeh.2013.02.007

85. Boers M. Add-on or step-up trials for new drug development in rheumatoid arthritis: a new standard? Arthritis Rheum. 2003; 48(6):1481-3. DOI: 10.1002/art.11141 [PubMed: 12794813]

86. Ottolenghi L, Bertele V, Garattini S. Limits of add-on trials: antirheumatic drugs. Eur J Clin Pharmacol. 2009; 65(1):33-41. DOI: 10.1007/s00228-008-0545-z [PubMed: 18762934]

87. Hirota T, Schwartz S, Correll CU. Alpha-2 agonists for attention-deficit/hyperactivity disorder in youth: a systematic review and meta-analysis of monotherapy and add-on trials to stimulant therapy. J Am Acad Child Adolesc Psychiatry. 2014; 53(2):153-73. DOI: 10.1016/j.jaac. 2013.11.009 [PubMed: 24472251]

88. Feifel D. The Use of Placebo-Controlled Clinical Trials for the Approval of Psychiatric Drugs: Part II-Ethical Considerations Related to the Individual Participant. Psychiatry (Edgmont). 2009; 6(12): 19-25.

89. MacDonald K, Feifel D. Helping Oxytocin Deliver: Considerations in the Development of Oxytocin-Based Therapeutics for Brain Disorders. Frontiers in Neuroscience. 2013 In Press.

90. Figueira ML, Ouakinin S. Gender-related endocrinological dysfunction and mental disorders. Curr Opin Psychiatry. 2010; 23(4):369-72. DOI: 10.1097/YCO.0b013e3283399b86 [PubMed: 20495459]

91. Mendrek A, Stip E. Sexual dimorphism in schizophrenia: is there a need for gender-based protocols? Expert Rev Neurother. 2011; 11(7):951-9. DOI: 10.1586/ern.11.78 [PubMed: 21721913]

92. Champagne F, Diorio J, Sharma S, Meaney MJ. Naturally occurring variations in maternal behavior in the rat are associated with differences in estrogen-inducible central oxytocin receptors. Proc Natl Acad Sci U S A. 2001; 98(22):12736-41. DOI: 10.1073/pnas.221224598 [PubMed: 11606726]

93. Patisaul HB, Scordalakes EM, Young LJ, Rissman EF. Oxytocin, but not oxytocin receptor, is rRegulated by oestrogen receptor beta in the female mouse hypothalamus. J Neuroendocrinol. 2003; 15(8):787-93. [PubMed: 12834440]

94. Murakami G, Hunter RG, Fontaine C, Ribeiro A, Pfaff D. Relationships among estrogen receptor, oxytocin and vasopressin gene expression and social interaction in male mice. Eur J Neurosci. 2011; 34(3):469-77. DOI: 10.1111/j.1460-9568.2011.07761.x [PubMed: 21749489]

95. Popeski N, Amir S, Diorio J, Woodside B. Prolactin and oxytocin interaction in the paraventricular and supraoptic nuclei: effects on oxytocin mRNA and nitric oxide synthase. J Neuroendocrinol. 2003; 15(7):687-96. [PubMed: 12787053]

96. Uvnas-Moberg K, Alster P, Svensson TH. Amperozide and clozapine but not haloperidol or raclopride increase the secretion of oxytocin in rats. Psychopharmacology (Berl). 1992; 109(4): 473-6. [PubMed: 1365865]

97. Kiss A, Bundzikova J, Pirnik Z, Mikkelsen JD. Different antipsychotics elicit different effects on magnocellular oxytocinergic and vasopressinergic neurons as revealed by Fos immunohistochemistry. J Neurosci Res. 2010; 88(3):677-85. DOI: 10.1002/jnr.22226 [PubMed: 19774673] 
98. Gordon I, Zagoory-Sharon O, Leckman JF, Feldman R. Oxytocin and the development of parenting in humans. Biol Psychiatry. 2010; 68(4):377-82. DOI: 10.1016/j.biopsych.2010.02.005 [PubMed: 20359699]

99. Holt-Lunstad J, Birmingham W, Light KC. The influence of depressive symptomatology and perceived stress on plasma and salivary oxytocin before, during and after a support enhancement intervention. Psychoneuroendocrinology. 2011; 36(8):1249-56. DOI: 10.1016/j.psyneuen. 2011.03.007 [PubMed: 21507578]

100. Domes G, Lischke A, Berger C, Grossmann A, Hauenstein K, Heinrichs M, et al. Effects of intranasal oxytocin on emotional face processing in women. Psychoneuroendocrinology. 2010; 35(1):83-93. DOI: 10.1016/j.psyneuen.2009.06.016 [PubMed: 19632787]

101. Bartz JA, Zaki J, Bolger N, Ochsner KN. Social effects of oxytocin in humans: context and person matter. Trends Cogn Sci. 2011; 15(7):301-9. DOI: 10.1016/j.tics.2011.05.002 [PubMed: 21696997]

102. Macdonald KS. Sex, receptors, and attachment: a review of individual factors influencing response to oxytocin. Front Neurosci. 2012; 6:194.doi: 10.3389/fnins.2012.00194 [PubMed: 23335876]

103. Walss-Bass C, Fernandes JM, Roberts DL, Service H, Velligan D. Differential correlations between plasma oxytocin and social cognitive capacity and bias in schizophrenia. Schizophr Res. 2013; doi: 10.1016/j.schres.2013.04.003

104. Linkowski P, Geenen V, Kerkhofs M, Mendlewicz J, Legros JJ. Cerebrospinal fluid neurophysins in affective illness and in schizophrenia. Eur Arch Psychiatry Neurol Sci. 1984; 234(3):162-5. [PubMed: 6489403]

105. Beckmann H, Lang RE, Gattaz WF. Vasopressin--oxytocin in cerebrospinal fluid of schizophrenic patients and normal controls. Psychoneuroendocrinology. 1985; 10(2):187-91. 0306-4530(85)90056-3 [pii]. [PubMed: 4034849]

106. Legros JJ, Gazzotti C, Carvelli T, Franchimont P, Timsit-Berthier M, von Frenckell R, et al. Apomorphine stimulation of vasopressin- and oxytocin-neurophysins. Evidence for increased oxytocinergic and decreased vasopressinergic function in schizophrenics. Psychoneuroendocrinology. 1992; 17(6):611-7. [PubMed: 1287681]

107. Mai JK, Berger K, Sofroniew MV. Morphometric evaluation of neurophysin-immunoreactivity in the human brain: pronounced inter-individual variability and evidence for altered staining patterns in schizophrenia. J Hirnforsch. 1993; 34(2):133-54. [PubMed: 8228177]

108. Glovinsky D, Kalogeras KT, Kirch DG, Suddath R, Wyatt RJ. Cerebrospinal fluid oxytocin concentration in schizophrenic patients does not differ from control subjects and is not changed by neuroleptic medication. Schizophr Res. 1994; 11(3):273-6. [PubMed: 7910756]

109. Souza RP, Ismail P, Meltzer HY, Kennedy JL. Variants in the oxytocin gene and risk for schizophrenia. Schizophr Res. 2010; 121(1-3):279-80. DOI: 10.1016/j.schres.2010.04.019 [PubMed: 20547038]

110. Watanabe Y, Kaneko N, Nunokawa A, Shibuya M, Egawa J, Someya T. Oxytocin receptor (OXTR) gene and risk of schizophrenia: case-control and family-based analyses and metaanalysis in a Japanese population. Psychiatry Clin Neurosci. 2012; 66(7):622.doi: 10.1111/j. 1440-1819.2012.02396.x

111. Teltsh O, Kanyas-Sarner K, Rigbi A, Greenbaum L, Lerer B, Kohn Y. Oxytocin and vasopressin genes are significantly associated with schizophrenia in a large Arab-Israeli pedigree. Int J Neuropsychopharmacol. 2012; 15(3):309-19. DOI: 10.1017/S1461145711001374 [PubMed: 21899794]

112. Fischer-Shofty M, Shamay-Tsoory SG, Levkovitz Y. Characterization of the effects of oxytocin on fear recognition in patients with schizophrenia and in healthy controls. Front Neurosci. 2013; 7:127.doi: 10.3389/fnins.2013.00127 [PubMed: 23882178]

113. Horta de Macedo LR, Zuardi AW, Machado-de-Sousa JP, Chagas MH, Hallak JE. Oxytocin does not improve performance of patients with schizophrenia and healthy volunteers in a facial emotion matching task. Psychiatry Res. 2014; 220(1-2):125-8. DOI: 10.1016/j.psychres. 2014.07.082 [PubMed: 25190346]

114. Bujanow W. Hormones in the treatment of psychoses. Br Med J. 1972; 4(5835):298. 
115. Bujanow W. Letter: Is oxytocin an anti-schizophrenic hormone? Can Psychiatr Assoc J. 1974; 19(3):323. [PubMed: 4841051]

116. Bakharev VD, Tikhomirov SM, Lozhkina TK. Psychotropic properties of oxytocin. Probl Endokrinol (Mosk). 1984; 30(2):37-41. 


\section{Key Points}

1. Current antipsychotic drugs have produced their greatest benefit in treating the positive symptoms of schizophrenia but have limited therapeutic effects on the negative symptoms and cognitive deficits in patients who suffer from this devastating disorder.

2. The convergent findings from recent small clinical trials and studies of the endogenous oxytocin system in patients with schizophrenia are encouraging, although not completely consistent. Together, they suggest that oxytocin may reduce the currently treatment resistant debilitating negative symptoms and social cognitive deficits, as well as the positive symptoms.

3. Despite these encouraging preliminary findings, many issues still need to be addressed while optimizing oxytocin or oxytocin-mimetics to alleviate symptoms of schizophrenia. 


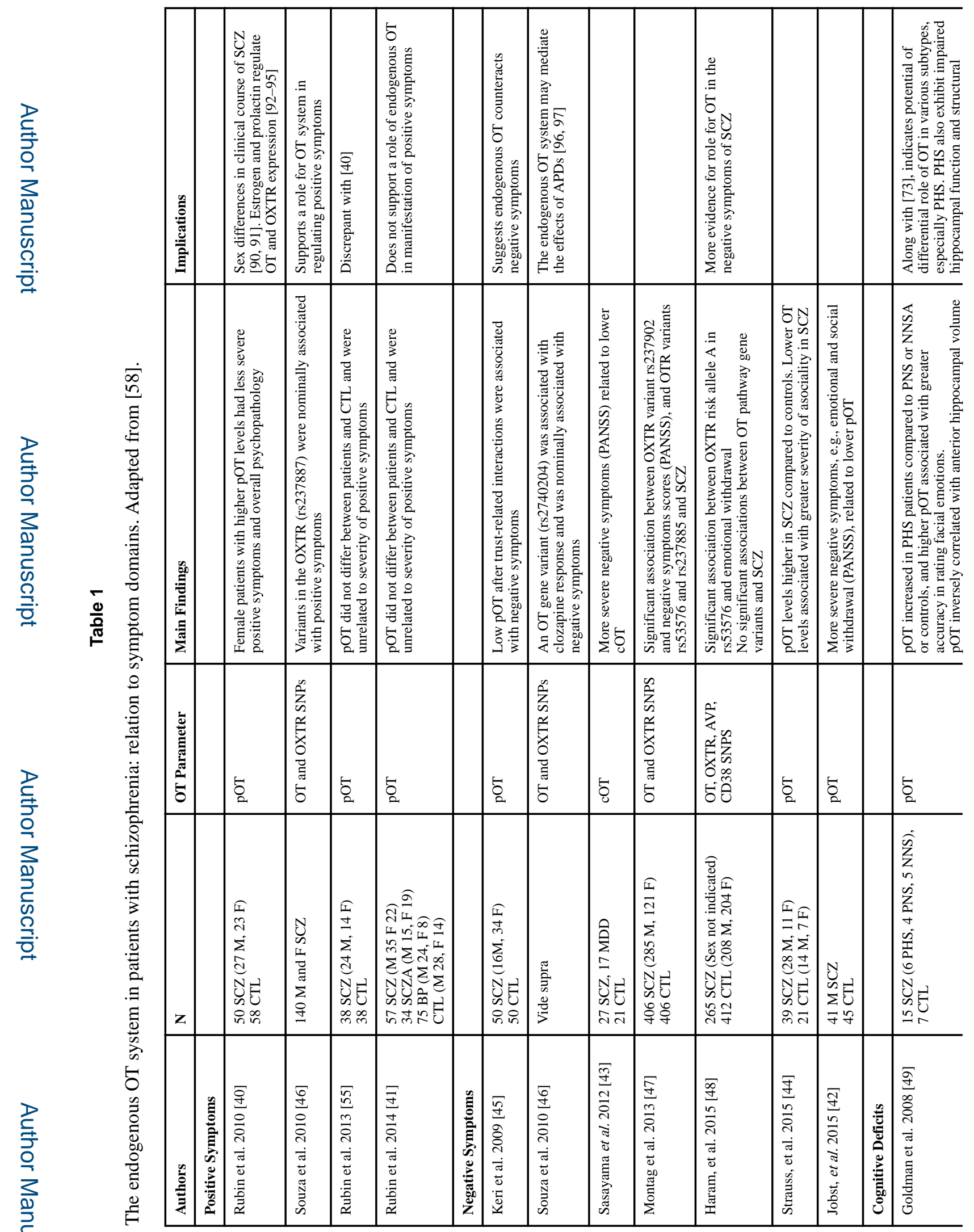

CNS Drugs. Author manuscript; available in PMC 2017 June 05. 


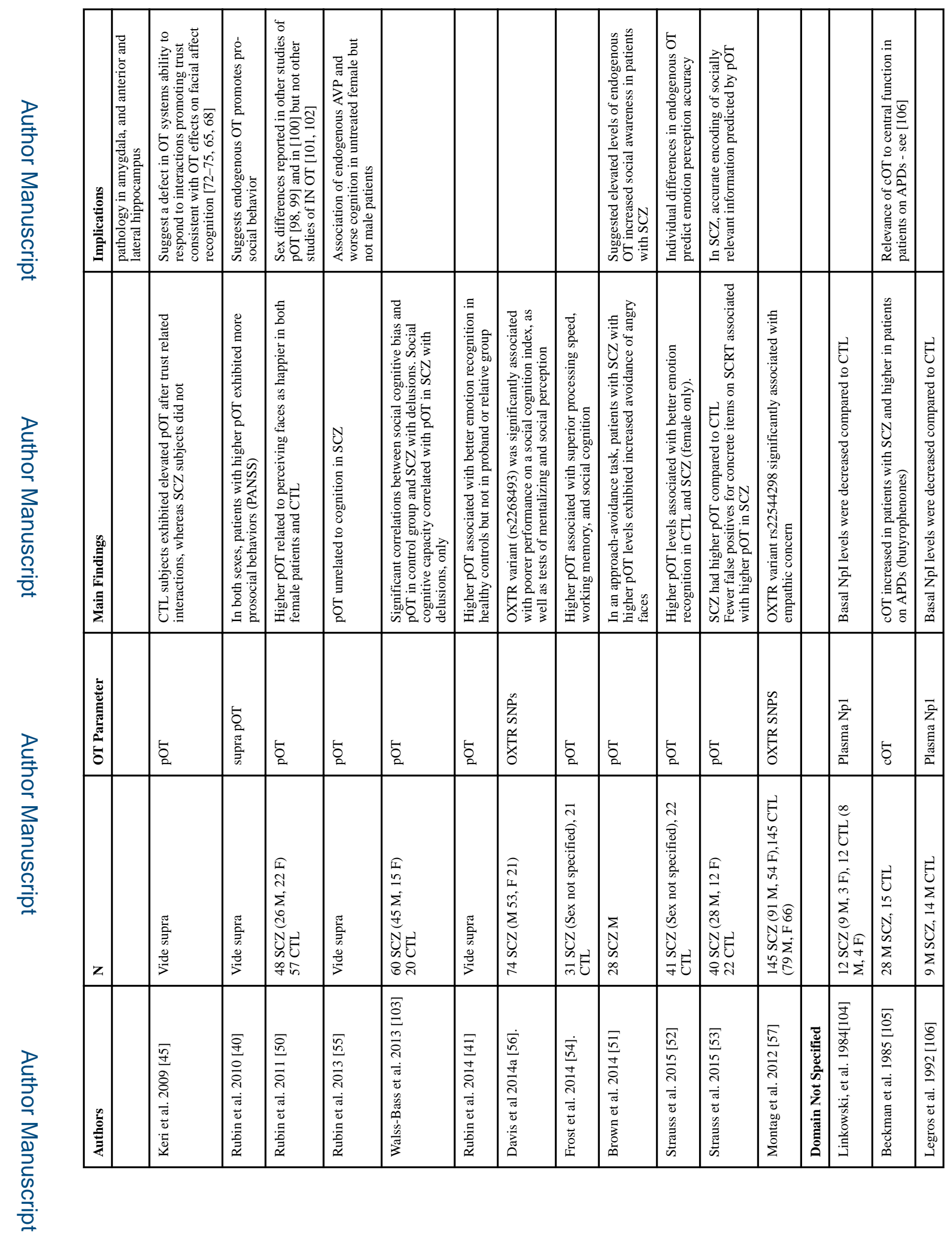

CNS Drugs. Author manuscript; available in PMC 2017 June 05. 


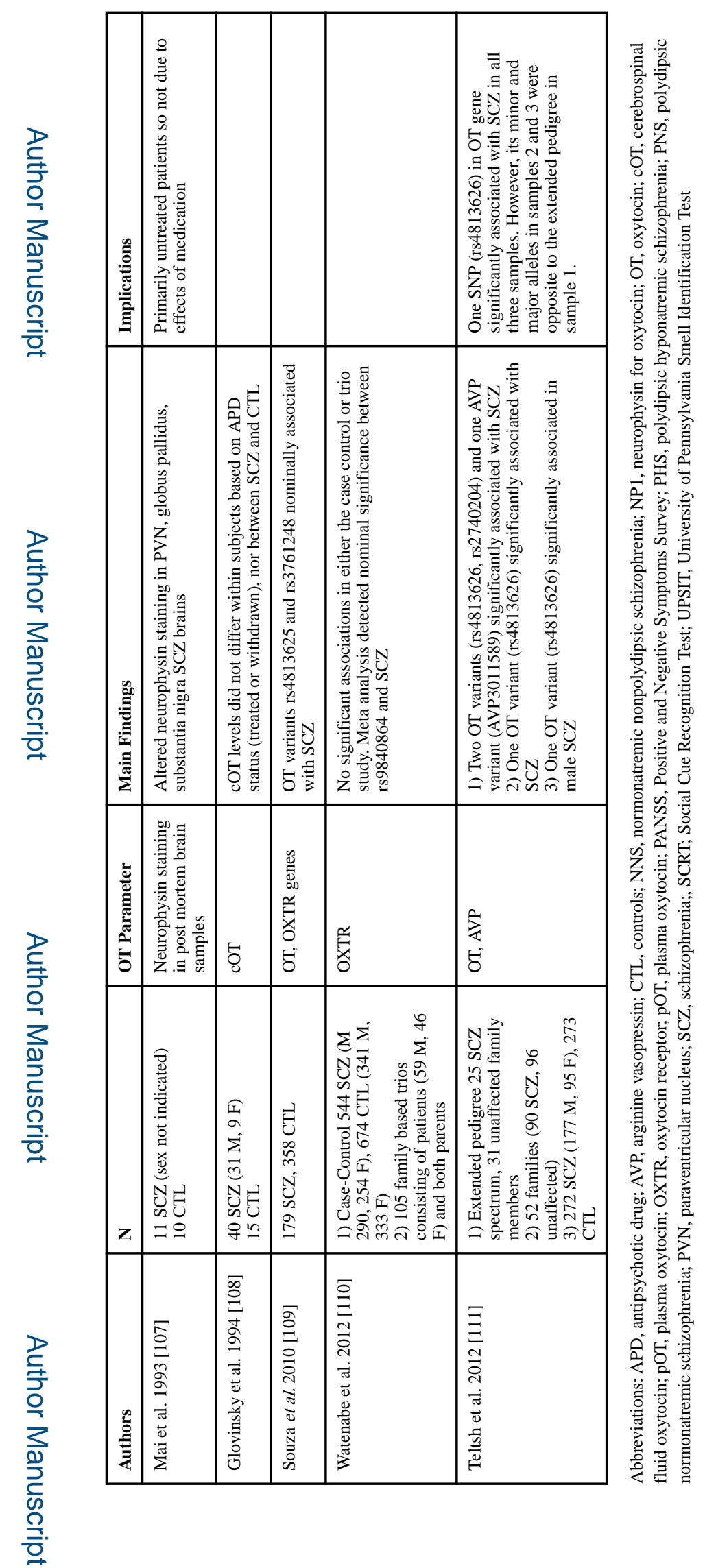

CNS Drugs. Author manuscript; available in PMC 2017 June 05. 


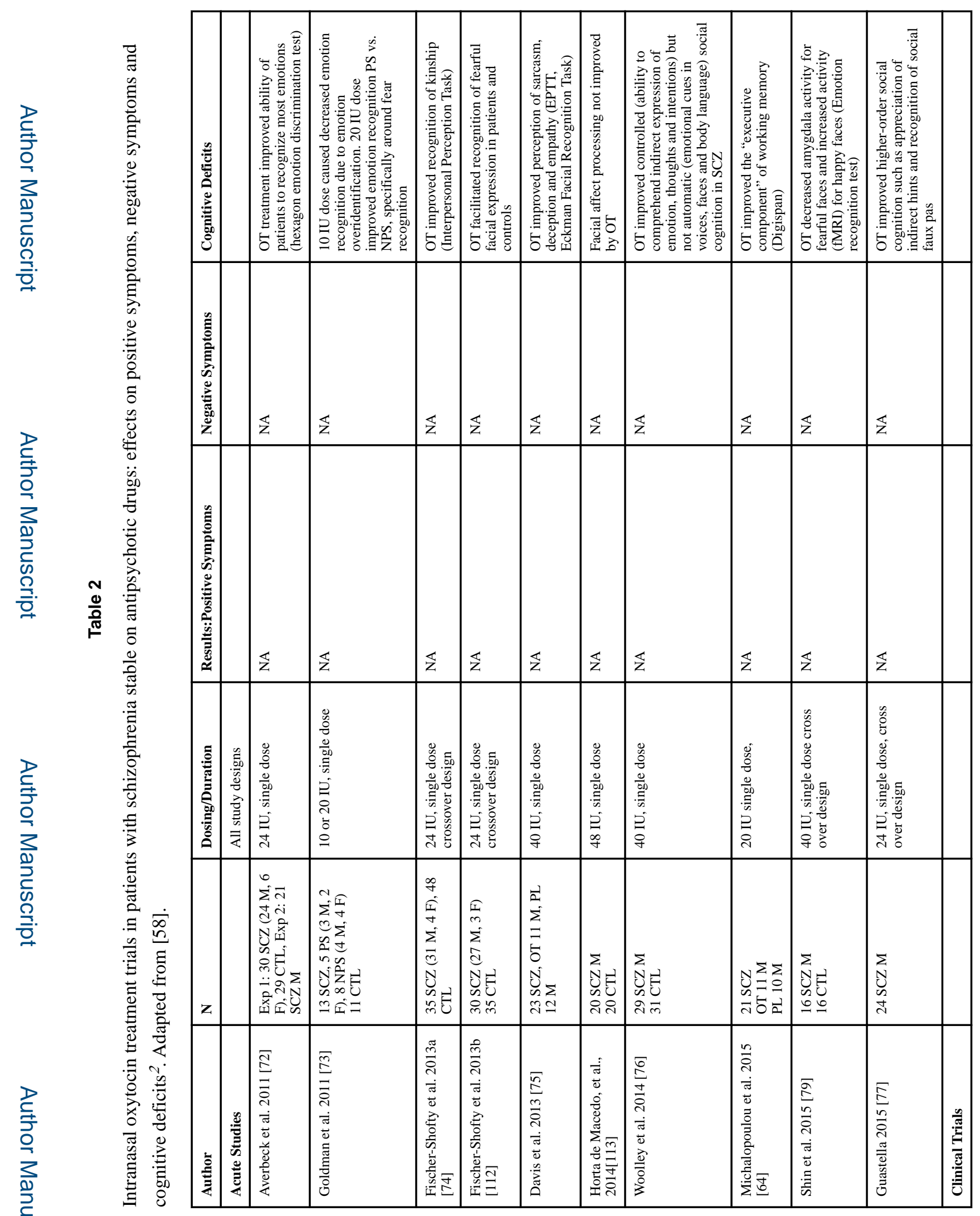

CNS Drugs. Author manuscript; available in PMC 2017 June 05 


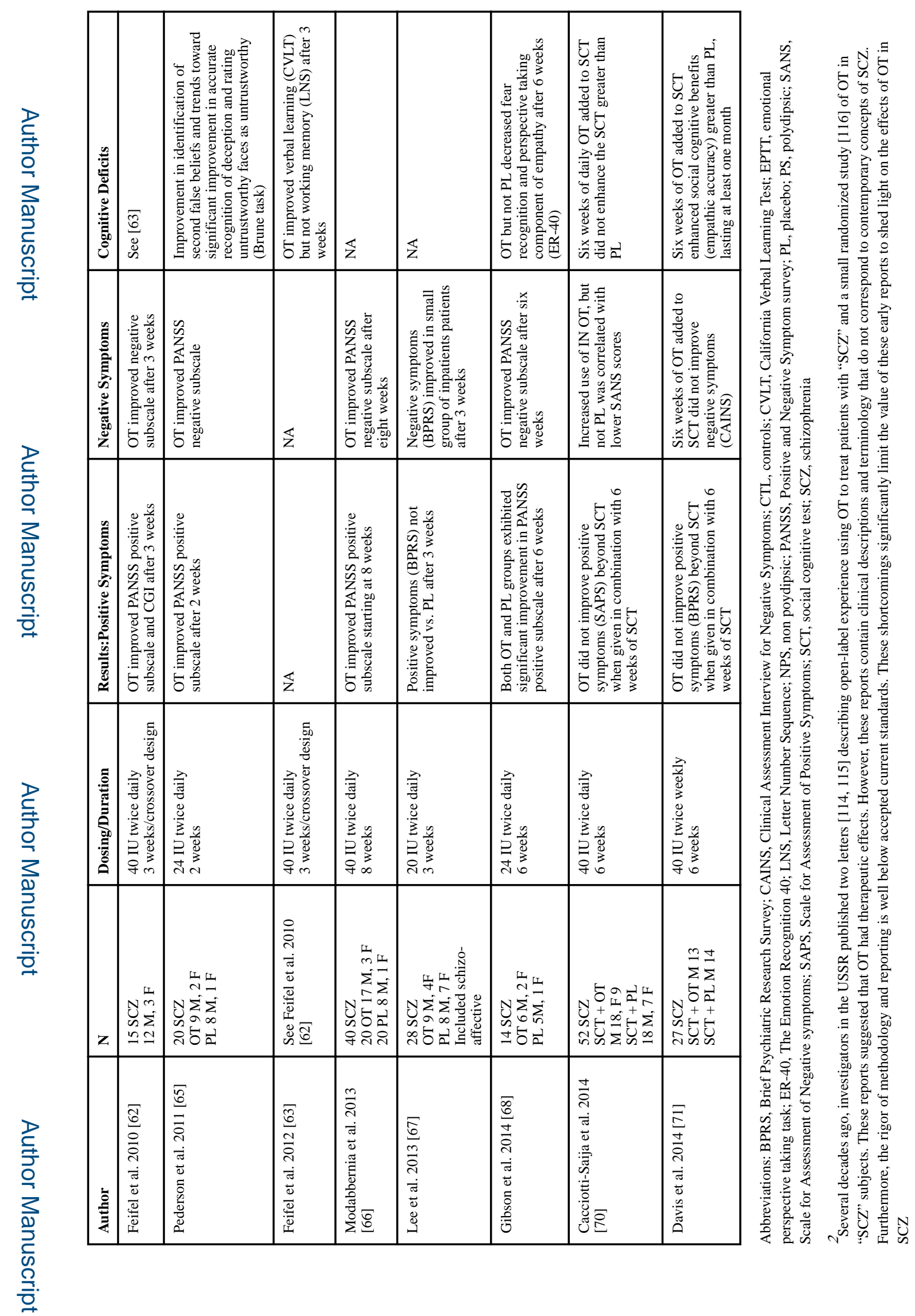

CNS Drugs. Author manuscript; available in PMC 2017 June 05. 